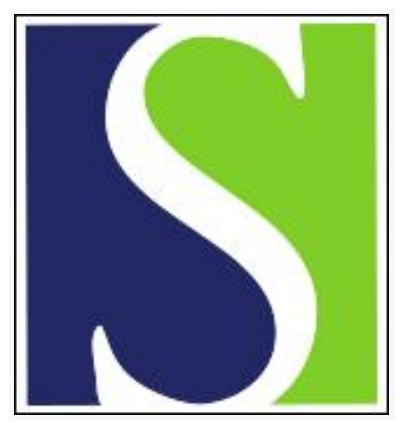

Scand J Work Environ Health 2005;31(5):367-374

https://doi.org/10.5271/sjweh.920

Issue date: Oct 2005

Reduced productivity after sickness absence due to musculoskeletal disorders and its relation to health outcomes by Lötters F, Meerding W-J, Burdorf A

Affiliation: Department of Public Health, Erasmus MC, University Medical Center Rotterdam, Rotterdam, The Netherlands. f.lotters@erasmusmc.nl

The following articles refer to this text: 2007;33(2):122-130;

2007;33(3):161-164; 2008;34(2):120-132; 2009;35(4):301-308;

2010;36(1):25-33; 2010;36(6):473-483; 2011;37(2):99-108;

2011;37(6):481-493; 2012;38(2):89-91; 2015;41(1):102-104

Key terms: health outcome; MSD; musculoskeletal disorder; presenteeism; productivity; productivity costs; return to work; sickness absence

This article in PubMed: www.ncbi.nlm.nih.gov/pubmed/16273963

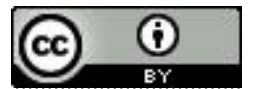




\title{
Reduced productivity after sickness absence due to musculoskeletal disorders and its relation to health outcomes
}

\author{
by Freek Lötters, MSc, ${ }^{1,2}$ Willem-Jan Meerding, MSc, ${ }^{1}$ Alex Burdorf, $P h D^{1}$
}

\begin{abstract}
Lötters F, Meerding W-J, Burdorf A. Reduced productivity after sickness absence due to musculoskeletal disorders and its relation to health outcomes. Scand J Work Environ Health 2005;31(5):367-374.

Objectives This prospective cohort study quantified the reduced productivity of workers on full duty after sickness absence from a musculoskeletal disorder and determined the effect of health parameters such as perceived pain, functional disability, and general health on reduced productivity.

Methods Workers were included who were returning to work from 2- to 6-week sickness absence due to a musculoskeletal disorder. Self-administered questionnaires at baseline, after return to work, and at a 12-month follow-up were used to collect information on productivity and health status. Logistic regression analyses evaluated the determinants of reduced productivity and determined the level of productivity loss shortly after return to work.

Results Reduced productivity was prevalent for $60 \%$ of the workers after they returned to work, and for $40 \%$ still at the 12-month follow-up. The initial musculoskeletal disorder caused $75 \%$ of the productivity loss shortly after return to work and $60 \%$ at the follow-up. Among those with productivity loss, the median loss for an 8-hour workday was 1.6 hours shortly after return to work and also at the follow-up. Worse physical health, more functional disability, and poorer relations with the supervisor were associated with productivity loss shortly after return to work, whereas recurrent sick leave was the greatest predictor of productivity loss at the follow-up.

Conclusions Reduced productivity was common among workers returning to full duty after sickness absence due to a musculoskeletal disorder. Productivity loss illustrates the importance of the timing of return to work, especially among workers with residual functional disability after return to work. Moreover, the supervisor should be engaged early in the return-to-work process to guarantee an early, sustainable, and productive return to work for the employee.
\end{abstract}

Key terms return to work; presenteeism; productivity costs.

Musculoskeletal disorders are well recognized as a major public health problem with substantial human and economic costs $(1,2)$. In the general Dutch population the 12-month prevalence for musculoskeletal disorders has been estimated to be around $75 \%$, of which $44 \%$ is due to low-back pain and $45 \%$ to neck and shoulder complaints (3). These high prevalences lead to substantial costs, such as hospital care, general practice costs, and paramedical costs. These direct costs were estimated to be $7.3 \%$ of the allocated health care costs in The Netherlands, thereby being one of most expensive health areas (4). In addition, indirect costs due to sickness absence and work disability are substantial since musculoskeletal disorders account for $31 \%$ of the total costs of long-term work disability.
However, the aforementioned aspects of direct and indirect costs do not cover the full burden of musculoskeletal disorders, because a health problem may also affect work ability, causing reduced productivity while the worker is still on the job (ie, sickness presenteeism) (5-7). Hence, both absenteeism and presenteeism should be taken into consideration when indirect costs due to musculoskeletal disorders are calculated. In a study among the Swedish workforce approximately one-third of all workers reported that they had gone to work twice or more during the preceding year, despite the feeling that, in light of their perceived health status, they should have taken sick leave (6). Brouwer et al (5) found that, on an average workday, over $7 \%$ of the workers experienced health problems while at work, the result being

1 Department of Public Health, Erasmus MC, University Medical Center Rotterdam, Rotterdam, The Netherlands.

2 Department of Occupational Health \& Safety Services, University Medical Center Rotterdam, The Netherlands.

Correspondence to: Freek Lötters, Department of Occupational Health \& Safety Services (Center Location Z-536), University Medical Center Rotterdam, PO Box 2040, 3000 CA Rotterdam, The Netherlands. [E-mail: f.lotters@erasmusmc.nl] 
an estimated productivity loss of $10 \%$ of the workhours. In a study of telephone customer-service employees, $32 \%$ failed to meet the productivity standard due to health problems, resulting in lost productivity time of almost 4 hours per week (7).

Little information is available on productivity loss due to musculoskeletal disorders. Hagberg et al (8) determined reduced productivity among computer users due to neck-shoulder or upper-extremity disorders and observed a productivity loss of approximately 4 hours per week for $10 \%$ of the workers with a neck-shoulder or upper-extremity disorder. In an extensive study among over 28000 workers, a productivity loss of approximately 4 hours per week was found for $8 \%$ of the workers with a musculoskeletal disorder (9). Furthermore, it is known that many workers who have returned to full duty still report some functional limitations due to the initial musculoskeletal disorder $(10,11)$. Evanoff et al found (10) that, despite the fact that $83 \%$ of the cohort with initial sick leave due to a musculoskeletal disorder worked full duty after 6 months of follow-up, $24 \%$ of these workers reported that they considered themselves to be still disabled by the disorder. These findings suggest that residual disability may lead to productivity loss and hence that indirect costs of musculoskeletal disorders may continue after return to work. However, little is known about reduced productivity after a sickness absence due to a musculoskeletal disorder and, subsequently, about the health parameters that determine such reduced productivity.

Hence the aim of this study was to quantify the reduced productivity of workers on full duty after sickness absence due to a musculoskeletal disorder and to determine how reduced productivity is affected by health parameters such as perceived pain, functional disability, and general health.

\section{Study population and methods}

\section{Participants and study design}

A longitudinal study with 12 months of follow-up was conducted. Self-administered questionnaires were used at baseline, at return to work, and 12 months after the first day of sick leave. The participants were enrolled by being selected from the absenteeism register of a large Dutch occupational health service or by the occupational health physicians during their consultations. For inclusion in the study via the absenteeism register, the researcher selected the participants who were on sick leave due to nonspecific musculoskeletal complaints for 2 to 6 weeks, as registered by the occupational physician using the CAS code system (12). With the second inclusion method the occupational health physician was asked to include all workers with nonspecific musculoskeletal disorders who attended his or her consulting hour. People were excluded when they suffered from a specific underlying pathology, such as a fractured leg, prolapsed intervertebral disc, or carpal tunnel syndrome. These specific pathologies were identified and coded by the occupational physician using the CAS code system (12). On the basis of the initial diagnosis, the participants had to fill out a diagnosis-specific questionnaire (ie, low-back, hip, knee, ankle-foot, neck-shoulder, or wrist-hand-elbow). After signing an informed consent, the participants were sent the baseline questionnaire and, if necessary, two reminders within 3 weeks. The dates of the start and end of sick leave were obtained from the medical records of the occupational health service. Return to work was defined as returning to full duty in the original job. The participants were sent a follow-up questionnaire within the first 2 weeks of their return to work and 12 months after the first day of sick leave. Those who did not return to work within 12 months were not eligible for this study.

\section{Contents of the questionnaires}

The baseline questionnaire gathered information on personal factors, work-related factors, the nature and severity of the musculoskeletal disorder, functional disability, and general health. The main individual characteristics obtained were age, gender, body mass index, marital status, education, and employment status (13).

Perceived physical workload was rated on a 10-point numerical rating scale, with 0 as not strenuous at all and 10 as very strenuous (14). For psychosocial factors at work the Job Content Questionnaire was used (15). With this model, three dimensions can be distinguished, work demands (11 items), skill discretion (6 items), and decision authority (11 items). For each item a four-point scale was used between 0 (never) and 3 (always). Subsequently, a sum score by dimension was calculated. A 10-point numerical scale was used to determine the relation with colleagues and supervisors, with 0 as "don't get along well at all" and 10 as "get along very well" (14)

We used a 10-point numerical rating scale to determine the level of perceived pain, with 0 as "no pain at all" and 10 as "worse as it can get" (16). Pain intensity was measured for the body part that represented the initial sick-leave diagnosis. Functional disability was assessed by the Roland Morris Disability Questionnaire for back complaints (17) and comparable questionnaires for other joints derived from the Roland Morris Questionnaire. For the latter purpose we changed the phrase "because of my back" into "because of my neck", "because of my knee", and the like. Furthermore, for use for neck, shoulder and elbow-wrist-hand complaints, six items concerning walking and standing were substituted 
by corresponding items from the physical dimension of the Sickness Impact Profile concerning disability due to upper-extremity disorders (18). The Sickness Impact Profile is a general health questionnaire that forms the basis for the Roland-Morris Disability Questionnaire for low-back pain (17). Finally, general health was measured by the 12-item Short-form Health Survey (SF-12) (19) and the EuroQuality of Life-5 dimension Questionnaire (EuroQol-5d) (20). The SF-12 consists of eight dimensions (ie, general health, physical functioning, rolephysical, bodily pain, vitality, role-emotional, social functioning, and mental health). These dimensions were summarized into a physical component summary (PCS12) and a mental component summary (MCS12) (21). The EuroQol questionnaire distinguishes five dimensions (ie, mobility, self-care, daily activity, pain, and anxiety or depression). From these items a general health index was calculated (22), which was transformed to a 0-100 scale. In addition, the EuroQol questionnaire was also used to measure general health by means of a thermometer (the EuroQol visual analoque scale) on a $0-100$ scale (20).

With the second questionnaire, administered shortly after the participants had returned to work in their original job, and the third questionnaire, filled out 12 months after the follow-up, we again gathered information on perceived pain, functional disability, and general health. With both questionnaires productivity after return to work was measured, using the quantity scale of the method described by Brouwer et al (23). The respondents were asked how much work they actually performed during regular hours on the most recent workday compared with a normal workday, using an 11point numerical scale with 0 presenting "nothing" and 10 representing "normal quantity". For the quantity loss, the score was normalized to the number of workhours per day with the formula: $\mathrm{Q}_{\mathrm{T}}=[(10$-quantity score $) /$ 10] $\times$ workhours per day (23). In addition, we asked for the reason behind the self-reported productivity loss. The reasons were classified as the initial musculoskeletal disorder causing the prior sick leave, other health problems, work-related problems such as equipment failure, and miscellaneous reasons.

\section{Data analysis}

For reasons of comparability, only the participants who filled out both the return-to-work questionnaire and the 12-month follow-up questionnaire were included in the analysis. Since we were interested in productivity loss after return to work due to a musculoskeletal disorder, we distinguished the participants that reported the initial musculoskeletal disorder as the reason for their productivity loss from those that did not report productivity loss due to a musculoskeletal disorder.
The prevalence of productivity loss due to a musculoskeletal disorder was determined by all of the participants reporting less than normal productivity (score $<10$ ) due to a musculoskeletal disorder. The level of productivity loss shortly after return to work was calculated for the workers who reported lost worktime due to a musculoskeletal disorder. The median productivity loss was used to dichotomize productivity into high and low productivity loss. Risk factors for the occurrence of productivity loss and the determinants of the high versus low productivity loss were derived through a stepwise backward logistic regression. In both analyses, perceived pain, functional disability, physical health, mental health, general health (EQ-VAS), low-back pain or other musculoskeletal disorders, duration of prior sickness absence, perceived physical workload, perceived psychosocial workload, relation with colleagues, and relation with supervisors were the independent variables. In these analyses, two models were built, one model with the baseline values of the health variables and subsequently a model with the cross-sectionally measured values of these variables. All of the results were adjusted for age and gender, independent of their significance.

A third analysis was performed to determine whether a recurrent sickness absence during the follow-up influenced the self-reported reduced productivity at the end of the follow-up and, retrospectively, shortly after return to work. A recurrent sickness absence period was defined as at least one sick leave due to the same musculoskeletal disorder that caused the initial sickness absence.

\section{Results}

\section{Study population}

The occupational physicians included 140 participants, and 307 participants were selected from the absenteeism records. Of the latter group, 59\% ( $\mathrm{N}=181)$ agreed to participate in the study. Of the 321 participants willing to participate, 287 returned the baseline questionnaire (response 89\%). For the final sample 253 participants remained, because 34 participants had already returned to work fully before completing the baseline questionnaire. Of the 253 participants, 232 (91\%) returned to work fully within the 12-month follow-up period. In this sample of 232 participants, 204 returned the questionnaire at the time of their return to work (response 88\%), 196 returned the 12-month follow-up questionnaire (response 84\%), and 184 participants filled out all three questionnaires (response 79\%).

The mean duration of sickness absence at the time of the response on the baseline questionnaire was 34 (SD 14) days. The median sickness absence duration for the 204 participants with return to work was 84 days, 
ranging from 15 to 362 days. The median follow-up duration after return to work was 261 days, ranging from 42 to 362 days. Most of the respondents were blue-collar workers, from a wide range of industrial settings. Another substantial part of the participants worked in the health care sector. The mean age of the participants was 43 (SD 9) years, most of the participants had a lower educational background (56\%), and most were male (73\%). Most of the participants were on sickness absence due to low-back pain $(51 \%)$, followed by neckshoulder pain $(27 \%)$, upper-extremity disorders (13\%), and lower-extremity disorders $(9 \%)$.

\section{Productivity and health parameters}

Shortly after return to work, 111 participants (60\%) showed a loss in the amount of work done on a regular

Table 1. Prevalence of productivity loss and average productivity loss due to musculoskeletal disorders among workers with lost worktime who returned to work after a sickness absence due to a musculoskeletal disorder $(\mathrm{N}=184)$. ( $\mathrm{GM}=$ geometric mean, $\mathrm{GSD}$ = geometric standard deviation)

\begin{tabular}{|c|c|c|c|c|c|}
\hline \multirow[t]{2}{*}{ Time of measurement } & \multicolumn{2}{|c|}{ Prevalence } & \multicolumn{3}{|c|}{$\begin{array}{l}\text { Productivity loss } \\
\text { (in hours per day) }\end{array}$} \\
\hline & N & $\%$ & Median & nange & GM GSD \\
\hline Shortly after return to work & 83 & 45 & 1.6 & $0.6-5.3$ & 1.71 .8 \\
\hline At the 12-month follow-up & 44 & 24 & 1.6 & $0.8-6.0$ & 1.71 .8 \\
\hline
\end{tabular}

workday, of which $83(75 \%)$ reported production loss due to a musculoskeletal disorder. These numbers were $73(40 \%)$ and $44(60 \%)$ at the 12-month follow-up, respectively. Of the participants who reported reduced productivity due to a musculoskeletal disorder shortly after return to work, $67 \%$ did not report productivity loss due to a musculoskeletal disorder at the 12-month follow-up. Furthermore, the occurrence of productivity loss due to a musculoskeletal disorder at the 12-month follow-up was significantly lower than shortly after the return to work $\left(\chi^{2}=6.17, \mathrm{P}=0.01\right)$. The median productivity loss shortly after the return to work and at the 12month follow-up for the workers who reported lost worktime due to musculoskeletal disorders was 1.6 hours per day (table 1). Productivity loss after 12 months occurred significantly more for the workers with recurrent sick leave during the follow-up period $\left(\chi^{2}=11.30\right.$, $\mathrm{P}=0.001)$. Retrospectively, $58 \%$ of the workers that had had recurrent sick leave had productivity loss shortly after return to work $\left(\chi^{2}=5.09, \mathrm{P}=0.02\right)$.

A one-point increase on the functional disability scale, measured cross-sectionally, increased the odds ratio for reduced productivity due to a musculoskeletal disorder shortly after return to work by $11 \%$ and after 12 months of follow-up by $24 \%$ (table 2). A one-point increase in physical health decreased the odds ratio for productivity loss due to a musculoskeletal disorder shortly after return to work by $9 \%$. A better relation with supervisors was associated with a decrease in the

Table 2. Risk factors for reduced productivity due to a musculoskeletal disorder after return to work and after 12-months of follow-up ( $\mathrm{N}=184)$. ( $\mathrm{OR}=$ odds ratio, $95 \% \mathrm{Cl}=95 \%$ confidence interval)

\begin{tabular}{|c|c|c|c|c|c|c|c|c|}
\hline \multirow[t]{3}{*}{ Variables } & \multicolumn{4}{|c|}{ Productivity loss shortly after return to work } & \multicolumn{4}{|c|}{ Productivity loss at the 12-month follow-up } \\
\hline & \multicolumn{2}{|c|}{$\begin{array}{l}\text { Health variables } \\
\text { at baseline }\end{array}$} & \multicolumn{2}{|c|}{$\begin{array}{l}\text { Health variables } \\
\text { shortly after } \\
\text { return to work }\end{array}$} & \multicolumn{2}{|c|}{$\begin{array}{l}\text { Health variables } \\
\text { shortly after } \\
\text { return to work }\end{array}$} & \multicolumn{2}{|c|}{$\begin{array}{l}\text { Health variables } \\
\text { at the 12-month } \\
\text { follow-up }\end{array}$} \\
\hline & $\mathrm{OR}$ & $95 \% \mathrm{Cl}$ & OR & $95 \% \mathrm{Cl}$ & $\mathrm{OR}$ & $95 \% \mathrm{Cl}$ & OR & $95 \% \mathrm{Cl}$ \\
\hline Age (years) & 1.0 & $0.96-1.04$ & 0.97 & $0.93-1.01$ & 0.98 & $0.93-1.03$ & 0.96 & $0.92-1.02$ \\
\hline Gender (male versus female) & 1.31 & $0.96-1.04$ & 1.02 & $0.42-2.47$ & 0.79 & $0.31-2.02$ & 0.88 & $0.32-2.39$ \\
\hline $\begin{array}{l}\text { Musculoskeletal disorder } \\
\text { (low-back pain versus other) }\end{array}$ & 0.63 & $0.62-2.77$ & 0.63 & $0.29-1.38$ & 0.61 & $0.27-1.37$ & 0.49 & $0.19-1.26$ \\
\hline Perceived physical workload (0-10) & 1.05 & $0.89-1.24$ & 0.97 & $0.79-1.19$ & 0.98 & $0.79-1.23$ & 1.19 & $0.93-1.52$ \\
\hline Psychosocial workload (1/0) & 0.64 & $0.29-1.41$ & 0.56 & $0.24-1.31$ & 1.45 & $0.62-3.42$ & 1.72 & $0.60-4.94$ \\
\hline Relation with colleagues $(0-10)$ & 1.24 & $0.95-1.60$ & 1.15 & $0.83-1.58$ & 1.13 & $0.82-1.57$ & 1.28 & $0.95-1.72$ \\
\hline Relation with supervisor $(0-10)$ & $0.83^{b}$ & $0.69-0.99$ & $0.76^{c}$ & $0.60-0.95$ & 0.90 & $0.71-1.14$ & 0.86 & $0.67-1.11$ \\
\hline Perceived pain $(0-10)$ & 1.08 & $0.88-1.32$ & 1.01 & $0.84-1.22$ & 0.92 & $0.74-1.14$ & 0.96 & $0.75-1.22$ \\
\hline Functional disability (0-24) & 0.93 & $0.86-1.02$ & $1.11^{b}$ & $1.02-1.22$ & 1.07 & $0.97-1.18$ & $1.24^{d}$ & $1.14-1.35$ \\
\hline Physical health (0-100) & 0.96 & $0.92-1.01$ & $0.92^{c}$ & $0.87-0.97$ & $0.93^{c}$ & $0.89-0.98$ & $0.96^{e}$ & $0.91-1.01$ \\
\hline Mental health $(0-100)$ & $0.97^{b}$ & $0.94-0.99$ & 0.97 & $0.93-1.02$ & 0.97 & $0.93-1.02$ & 1.04 & $0.99-1.01$ \\
\hline Sickness absence (days) & 1.0 & $0.99-1.00$ & 1.0 & $0.93-1.00$ & 1.0 & $0.93-1.00$ & 1.0 & $0.99-1.01$ \\
\hline Recurrent sick leave $(1 / 0)$ & $\cdot$ & $\cdot$ & . & $\cdot$ & $2.63^{b}$ & $1.18-5.88$ & 1.48 & $0.55-4.00$ \\
\hline Explained variance of the final model & $7 \%$ & & $26 \%$ & & $11 \%$ & & $21 \%$ & \\
\hline
\end{tabular}

a Age and gender were forced into the model. The values of the nonsignificant variables were derived when dropped from the model.

b $P \leq 0.05$.

c $P \leq 0.01$.

d $P \leq 0.001$.

e $P \leq 0.10$ (when excluded from the model). 
prevalence of reduced productivity due to a musculoskeletal disorder shortly after the return to work (table 2). Recurrent sick leave during the follow-up was highly predictive for the occurrence of productivity loss at the 12-month follow-up [odds ratio (OR) 2.63, 95\% confidence interval $(95 \%$ CI $) 1.18-5.88]$. The explained variances of the occurrence of productivity loss shortly after return to work and after 12 months of follow-up were higher in the cross-sectional analyses $(26 \%$ and $21 \%$, respectively) than in the longitudinal analyses $(7 \%$ and $11 \%$, respectively).

None of the health variables measured at baseline contributed significantly to the prediction of the level of productivity loss shortly after the return to work. When measured cross-sectionally, only the level of perceived pain was significantly associated with the level of productivity loss. Although not statistically significant, having an upper-extremity disorder appeared to be associated more with the level of productivity loss than low-back pain was (table 3).

\section{Discussion}

Reduced productivity was found for $60 \%$ of the workers after return to work and for $40 \%$ at the 12 -month follow-up. The initial musculoskeletal disorder causing the prior sick leave was the cause for $75 \%$ of the participants to report productivity loss at the time of their return to work and for $60 \%$ at the 12 -month follow-up. Among those with self-reported productivity loss, the median productivity loss for an 8-hour workday due to a musculoskeletal disorder was 1.6 hours a day shortly after the return to work and also at the 12-month followup. Poorer physical health, more functional disability, and a poorer relation with the supervisor were associated with productivity loss shortly after the return to work, whereas recurrent sick leave was the most common predictor for productivity loss at the12-month follow-up.

\section{Reduced productivity after return to work}

Our study confirmed previous findings that remaining at work while impaired by a health problem may result in a decrease in performance, as measured by reduced productivity $(7-9,23)$. The one study in which reduced productivity was measured shortly after return to work showed that about $20 \%$ of the workers experienced reduced productivity due to their health problems with an average productivity loss of approximately $7 \%$ (5). However, the mean duration of sickness absence in this study was 4.0 days, whereas, in our study, we included only workers who were already on sick leave for 2 to 6 weeks and had a median sick leave of 84 days. This
Table 3. Determinants of the level of reduced productivity loss shortly after return to work among those with lost worktime due to a musculoskeletal disorder $(\mathrm{N}=83)$. (outcome = productivity loss $>1.6$ hours per day, $\mathrm{OR}=$ odds ratio, $95 \% \mathrm{Cl}=95 \%$ confidence interval, MSD = musculoskeletal disorder, LBP = low-back pain)

\begin{tabular}{|c|c|c|c|c|}
\hline \multirow[t]{2}{*}{ Determinant } & \multicolumn{2}{|c|}{$\begin{array}{l}\text { Health variables } \\
\text { at baseline }\end{array}$} & \multicolumn{2}{|c|}{$\begin{array}{l}\text { Health variables } \\
\text { shortly after } \\
\text { return to work }\end{array}$} \\
\hline & $\mathrm{OR}$ & $95 \% \mathrm{Cl}$ & OR & $95 \% \mathrm{Cl}$ \\
\hline Age (years) & 1.0 & $0.94-1.05$ & 0.99 & $0.93-1.06$ \\
\hline Gender (male versus female) & 1.07 & $0.38-3.03$ & 0.70 & $0.22-2.18$ \\
\hline MSD (LBP versus other) & $0.43^{c}$ & $0.16-1.14$ & 0.54 & $0.18-1.69$ \\
\hline Perceived physical workload (0-10) & 0.91 & $0.69-1.18$ & 0.89 & $0.67-1.18$ \\
\hline Psychosocial workload (1/0) & 1.28 & $0.30-5.35$ & 1.47 & $0.36-5.90$ \\
\hline Relation with colleagues $(0-10)$ & 0.83 & $0.49-1.41$ & 0.85 & $0.49-1.46$ \\
\hline Relation with supervisor (0-10) & 0.81 & $0.60-1.11$ & $0.76^{c}$ & $0.55-1.06$ \\
\hline Perceived pain (0-10) & 1.17 & $0.79-1.73$ & $1.43^{b}$ & $1.01-1.86$ \\
\hline Functional disability (0-24) & $1.12^{+}$ & $0.99-1.26$ & 1.00 & $0.84-1.17$ \\
\hline Physical health $(0-100)$ & 1.05 & $0.94-1.17$ & 0.99 & $0.91-1.08$ \\
\hline Mental health $(0-100)$ & 0.97 & $0.93-1.02$ & 1.02 & $0.96-1.08$ \\
\hline Sickness absence (days) & 0.99 & $0.99-1.00$ & 1.00 & $0.99-1.01$ \\
\hline
\end{tabular}

Explained variance of the final model $0.1 \% \quad 11 \%$.

a Age and gender were forced into the model. Values of nonsignificant variables were derived when dropped from the model. b $P \leq 0.01$.

c $P \leq 0.10$ (when excluded from the model).

selection is probably the reason for the higher productivity loss found in our study. Brouwer et al (23) estimated that the average period of reduced performance for workers returning to work after a period of sickness absence was approximately 13 days. In our study we still found reduced performance after 30 days (ie, the average lap time between time of return to work and filling out the second questionnaire). In our population of workers who returned to work after a sickness absence due to a musculoskeletal disorder, we observed higher prevalences of reduced productivity due to a musculoskeletal disorder than in cross-sectional studies among all workers in a workforce $(8,9)$. Productivity loss shortly after return to work was associated with physical health and functional disability, indicating that residual disability among participants who return to work is important due to its effects on health and work productivity $(10,11,24,25)$.

A remarkable finding in this study was the strong association of the relation with the supervisor and productivity loss shortly after return to work. A one-point decrease on the relationship scale raised the odds of productivity loss by approximately $25 \%$. Moreover, a worse relationship with the supervisor measured at baseline was predictive of productivity loss shortly after return to work. Although not statistically significant, a better relationship with one's supervisor was also associated with a low level of productivity loss for the workers with lost worktime. These findings stress the fact that a 
supervisor should be engaged in the return-to-work process of the employee in order to guarantee an early and sustainable return to work. Recent studies have already emphasized the necessity of such occupational management strategies at the workplace in bringing the worker back to work in a more efficient way $(26,27)$.

\section{Health outcomes and reduced productivity}

Data on reduced productivity measured shortly after return to work and concomitant health status are scarce. In their review Loeppke et al (28) reported an association between the results of the SF12-questionnaire and productivity loss. Previous studies have shown that a poorer mental health status was associated with greater productivity loss $(7,29)$. This finding is in agreement with our finding that mental health status was predictive of productivity loss shortly after return to work. However, in our study, a poorer physical health status had a more profound impact on productivity loss. This finding is due the fact that we specifically studied workers on sick leave due to a musculoskeletal disorder and, thereby, expected more physical than mental problems. A study conducted among workers suffering from upper-extremity disorders showed that a greater persistence of pain was associated with a higher prevalence of productivity loss and a greater magnitude of productivity loss (8). The latter is in agreement with our finding that higher perceived pain intensity and an upper-extremity disorder were associated with more productivity loss.

Since productivity loss after return to work was strongly associated with functional disability and physical health and these health outcomes improved progressively in the first months after return to work (25), the present findings indicate that productivity loss occurred primarily among the workers whose recovery was still progressing during the follow-up. An additional analysis confirmed that $60 \%$ of the workers with a large improvement in physical health showed a significant productivity loss when compared with the workers (33\%) who showed no or minor improvement in physical health after returning to work $\left(\chi^{2}=13.8 ; \mathrm{P}=0.0002\right)$. For functional limitations, these numbers were, respectively, $59 \%$ and $35 \%\left(\chi^{2}=10.4 ; \mathrm{P}=0.001\right)$. In a large study of sickness presenteeism, Aronsson et al questioned whether there is a risk that the sickness presenteeism of today will become the sickness absenteeism of tomorrow (6). Retrospectively, we observed a strong association between recurrent sick leave and productivity loss shortly after return to work, this finding indicating that indeed sickness presenteeism increased the risk of future sickness absenteeism. Although one could argue that returning to work in a lower productivity state is better than prolonging the sickness absence and not being productive at all, the concomitant risk of recurrent sick leave suggests that the timing of initiating return to work is important.

The economic consequences of our findings can be illustrated by the following example. Suppose a worker with reduced productivity due to a musculoskeletal disorder of approximately $20 \%$ of an 8 -hour workday (as observed in our study), with an average annual salary for a Dutch worker of EUR 33000 (including 32\% employer costs) (30), and a duration of reduced productivity of 1 month after return to work. The yearly based workhours (without vacation hours, and nonworkhours due to festivity days) is 1650 . This presenteeism will incur productivity losses amounting to EUR 550 per worker per month after return to work (EUR $2750 \times$ 0.2 ), which roughly equals the costs of a sick leave period of 3.5 workdays (EUR 550 per month / EUR 160 per normal workday). However, the real costs of presenteeism are difficult to access since colleagues might compensate for a declined work performance and, therefore, reduce the associated costs of productivity loss (31). Moreover, we were unable to determine whether a good worker-supervisor relationship, as observed in this study, has increased the likelihood of performing modified work and, as a consequence, may have resulted in a lower perceived productivity loss.

\section{Limitations of the study}

Approximately $59 \%$ of the workers on sick leave for 2 6 weeks and selected from the absenteeism records of a large Dutch occupational health service responded to our request for participation in the study. Unfortunately, because of the methods used to select the participants and concomitant privacy aspects, we were not allowed to gather more information than that necessary when recruiting potential participants. Hence we were not able to describe the nonparticipants. Most workers on sick leave due to a musculoskeletal disorder return to work within a few weeks (32). Hence the low response can partly be explained by the fact that potential participants had already returned to work when they received our invitation to participate in the study. Furthermore, the participants were required to still be off work when filling out the questionnaire. Selection bias also may have occurred due to confounding by indication (ie, the occupational health physician suspecting a prolonged sickness absence and submitting these workers for inclusion). However, no differences in the baseline characteristics were found among participants, whether included by the occupational physician or selected from the absenteeism register (25). Moreover, the method of inclusion had no effect on the results of the study.

A drawback of our study is the fact that no objective measures of work productivity were used $(7,8,33)$. 
However, objective measures of productivity are difficult and time-consuming to obtain (7). In a single study, objective measurements of reduction in productivity were associated with health problems (7). Unfortunately, no studies have measured productivity loss both objectively and participatively in order to validate self-reported productivity loss, and hence no gold standard for productivity measurement is available (33). Moreover, the most accurate way of determining self-reported productivity loss is still subject to debate (31). In our study the productivity loss measured on a 11-point numerical scale $\left(\mathrm{Q}_{\mathrm{T}}\right)$ was converted to the number of workhours per day instead of the number of hours needed to compensate for lost work due to health problems, as, for example, is done with the Health and Labour Questionnaire (HLQ) (34). The problems with the HLQ method include the possibility that respondents may judge their efficiency by the potential amount of work they could have done rather than by the normal amount of work they usually do without health problems and thereby overestimate productivity loss. On the other hand, the HLQ method may underestimate real productivity loss when colleagues or temporary workers make up for lost work (5). The $\mathrm{Q}_{\mathrm{T}}$ method could be preferred since it indicates how much work was lost or had to be made up during overtime or during regular worktime, but the $\mathrm{Q}_{\mathrm{T}}$ may lead to an underestimate when lost work is compensated during regular workhours. Although both methods have a good correlation (5), the $\mathrm{Q}_{\mathrm{T}}$ appears to be more responsive to health indicators and job characteristics. A recent study showed that the external validity of the $\mathrm{Q}_{\mathrm{T}}$, in relation to actual production output, was acceptable (34). Referring to the comparison of methods, we chose a self-administered questionnaire in which questions on both health outcomes and productivity were included and could be filled out at the same time. Although the participants reported their productivity over a regular workday, and thus we were not able to establish the total duration of productivity loss, our findings indicate that $33 \%$ of the participants who reported productivity loss shortly after return to work still showed some decrease in work performance at the 12month follow-up.

\section{Concluding remarks}

In our study, reduced productivity was highly prevalent among workers who returned to full duty after a sickness absence due to a musculoskeletal disorder. The strong associations between functional disability and physical health indicate that workers with ongoing recovery from these health outcomes are at risk of productivity loss shortly after return to work. Productivity loss after return to work may result in recurrent sickness absence. This possibility illustrates the importance of the timing of facilitating return to work activities, especially for workers with residual functional disability and poorer physical health due to a musculoskeletal disorder after return to work. Moreover, our data emphasize that the supervisor should be engaged early in the return-to-work process in order to guarantee employees' early, sustainable, and productive return to work.

\section{Acknowledgments}

This study was conducted in co-operation with, and partly funded by, the Council of Medical and Health Research of The Netherlands (ZON-MW) and the ArboUnie, a leading Dutch occupational health service.

\section{References}

1. Barondes JA. Musculoskeletal disorders and the workplace: low back and upper extremities. Washington (DC): National Academy Press; 2001.

2. van Tulder MW, Koes BW, Bouter LM. A cost-of-illness study of back pain in The Netherlands. Pain 1995;62:233-40.

3. Picavet HS, Schouten JS. Musculoskeletal pain in the Netherlands: prevalences, consequences and risk groups, the DMC(3)-study. Pain 2003;102:167-78.

4. Meerding WJ, Bonneux L, Polder JJ, Koopmanschap MA, van der Maas PJ. Demographic and epidemiological determinants of healthcare costs in Netherlands: cost of illness study. BMJ 1998;317:111-5.

5. Brouwer WB, Koopmanschap MA, Rutten FF. Productivity losses without absence: measurement validation and empirical evidence. Health Policy 1999;48:13-27.

6. Aronsson G, Gustafsson K, Dallner M. Sick but yet at work: an empirical study of sickness presenteeism. J Epidemiol Community Health 2000;54:502-9.

7. Burton WN, Conti DJ, Chen CY, Schultz AB, Edington DW. The role of health risk factors and disease on worker productivity. J Occup Environ Med 1999;41:863-77.

8. Hagberg M, Tornqvist EW, Toomingas A. Self-reported reduced productivity due to musculoskeletal symptoms: associations with workplace and individual factors among whitecollar computer users. J Occup Rehabil 2002;12:151-62.

9. Stewart WF, Ricci JA, Chee E, Morganstein D, Lipton R. Lost productive time and cost due to common pain conditions in the US workforce. JAMA 2003;290:2443-54.

10. Evanoff B, Abedin S, Grayson D, Dale AM, Wolf L, Bohr P. Is disability underreported following work injury? J Occup Rehabil 2002;12:139-50.

11. Baldwin ML, Johnson WG, Butler RJ. The error of using returns-to-work to measure the outcomes of health care. Am J Ind Med 1996;29:632-41.

12. Landelijk Insituut Sociale Verzekeringen (LISV). CAS: Classificaties voor Arbo en SV. Utrecht (The Netherlands): Voorlichtingscentrum Sociale Verzekering; 1997.

13. Joung IM, Kunst AE, van Imhoff E, Mackenbach JP. Education, aging, and health: to what extent can the rise in educational level relieve the future health (care) burden associated 
with population aging in the Netherlands? J Clin Epidemiol 2000;53:955-63.

14. Hazard RG, Haugh LD, Reid S, Preble JB, MacDonald L. Early prediction of chronic disability after occupational low back injury. Spine 1996;21:945-51.

15. Karasek R, Brisson C, Kawakami N, Houtman I, Bongers P, Amick B. The Job Content Questionnaire (JCQ): an instrument for internationally comparative assessments of psychosocial job characteristics. J Occup Health Psychol 1998;3:32255.

16. Von Korff M, Jensen MP, Karoly P. Assessing global pain severity by self-report in clinical and health services research. Spine 2000;25:3140-51.

17. Roland M, Morris R. A study of the natural history of back pain, part I: development of a reliable and sensitive measure of disability in low-back pain. Spine 1983;8:141-4.

18. Bergner M, Bobbitt RA, Carter WB, Gilson BS. The Sickness Impact Profile: development and final revision of a health status measure. Med Care 1981;19:787-805.

19. Ware J Jr, Kosinski M, Keller SD. A 12-Item Short-Form Health Survey: construction of scales and preliminary tests of reliability and validity. Med Care 1996;34:220-33.

20. EuroQol Group. EuroQol: a new facility for the measurement of health-related quality of life. Health Policy 1990;16:199208.

21. Ware JE, Kosinski M, Keller SD. SF-12: how to score the SF12 Physical and Mental Health Summary scales. 4 ed. Lincoln (RI): QualityMetric inc; 2002.

22. Dolan P. Modeling valuations for EuroQol health states. Med Care 1997;35:1095-108.

23. Brouwer WB, van Exel NJ, Koopmanschap MA, Rutten FF. Productivity costs before and after absence from work: as important as common? Health Policy 2002;61:173-87.

24. Cooper JE, Tate RB, Yassi A. Components of initial and residual disability after back injury in nurses. Spine 1998;23:2118-22.

25. Lötters F, Hogg-Johnson S, Burdorf A. Health status, its perceptions, and effect on return to work and recurrent sick leave. Spine 2005;30:1086-92.
26. Loisel P, Durand MJ, Diallo B, Vachon B, Charpentier N, Labelle J. From evidence to community practice in work rehabilitation: the Quebec experience. Clin J Pain 2003;19:105-13.

27. Lemstra M, Olszynski WP. The effectiveness of standard care, early intervention, and occupational management in Workers' Compensation claims: part 2. Spine 2004;29:15739.

28. Loeppke R, Hymel PA, Lofland JH, Pizzi LT, Konicki DL, Anstadt GW, et al. Health-related workplace productivity measurement: general and migraine-specific recommendations from the ACOEM Expert Panel. J Occup Environ Med 2003;45:349-59.

29. Druss BG, Schlesinger M, Allen HM Jr. Depressive symptoms, satisfaction with health care, and 2-year work outcomes in an employed population. Am J Psychiatry 2001;158:731-4.

30. Centraal Bureau voor Statistiek (CBS) [Netherlands Central Bureau for Statistics]. Income data stratified by age, gender and educational level. Voorburg/Heerlen (The Netherlands): CBS; 2001

31. Koopmanschap M, Burdorf A, Jacob K, Meerding WJ, Brouwer W, Severens H. Measuring productivity changes in economic evaluation: setting the research agenda. Pharmacoeconomics 2005;23:47-54.

32. Frank JW, Brooker AS, DeMaio SE, Kerr MS, Maetzel A, Shannon HS, et al. Disability resulting from occupational low back pain, part II: what do we know about secondary prevention? a review of the scientific evidence on prevention after disability begins. Spine 1996;21:2918-29.

33. Greenberg PE, Birnbaum HG, Kessler RC, Morgan M, Stang P. Impact of illness and its treatment on workplace costs: regulatory and measurement issues. J Occup Environ Med 2001;43:56-63.

34. Meerding WJ, Ijzelenberg W, Koopmanschap MA, Severens JL, Burdorf A. Health problems lead to considerable productivity loss at work among workers with high physical load jobs. J Clin Epidemiol 2005;58:517-23.

Received for publication: 10 November 2004 